OPEN ACCESS

Edited by:

Renjie Chai,

Southeast University, China

Reviewed by:

Ling-Qing Yuan,

Central South University, China

Ge Zhang,

Hong Kong Baptist University,

Hong Kong

Seiji Fukumoto,

Tokushima University, Japan

*Correspondence:

Zhenlin Zhang

zhangz@@sjtu.edu.cn

Hua Yue

yueyinglonghua@163.com

Specialty section:

This article was submitted to

Molecular Medicine,

a section of the journa

Frontiers in Cell and Developmental

Biology

Received: 15 October 2020

Accepted: 16 April 2021

Published: 01 June 2021

Citation:

Lin X, Li S, Zhang Z and Yue H

(2021) Clinical and Genetic

Characteristics of 153 Chinese

Patients With X-Linked

Hypophosphatemia.

Front. Cell Dev. Biol. 9:617738.

doi: 10.3389/fcell.2021.617738

\section{Clinical and Genetic Characteristics of 153 Chinese Patients With $X$-Linked Hypophosphatemia}

\author{
Xiaoyun Lin, Shanshan Li, Zhenlin Zhang* and Hua Yue* \\ Shanghai Clinical Research Center of Bone Diseases, Department of Osteoporosis and Bone Diseases, Shanghai Sixth \\ People's Hospital Affiliated to Shanghai Jiao Tong University, Shanghai, China
}

X-linked hypophosphatemia $(X L H)$ is caused by inactivating mutations in the phosphateregulating endopeptidase homolog, $X$-linked (PHEX) gene, resulting in an excess of circulating intact fibroblast growth factor-23 (iFGF-23) and a waste of renal phosphate. In the present study, we retrospectively reviewed the clinical and molecular features of 153 Chinese patients, representing 87 familial and 66 sporadic cases with XLH. A total of 153 patients with XLH presented with signs or symptoms at a median age of 18.0 months (range, 9.0 months-26.0 years). Lower-limb deformity was the most frequent clinical manifestation, accounting for $79.1 \%$ (121/153). Biochemical screening showed increased serum levels of iFGF23 in patients with XLH, with a wide variation ranging from 14.39 to $730.70 \mathrm{pg} / \mathrm{ml}$. Median values of serum iFGF23 in pediatric and adult patients were $94.87 \mathrm{pg} / \mathrm{ml}$ (interquartile range: 74.27 $151.86 \mathrm{pg} / \mathrm{ml}$ ) and $72.82 \mathrm{pg} / \mathrm{ml}$ (interquartile range: $39.42-136.00 \mathrm{pg} / \mathrm{ml}$ ), respectively. Although no difference in circulating iFGF23 levels between these two groups was observed $(P=0.062)$, the proportion of patients with high levels of circulating iFGF23 (>42.2 $\mathrm{pg} / \mathrm{ml}$ ) was greater in the pediatric group than in the adult group $(P=0.026)$. Eighty-eight different mutations in 153 patients were identified, with 27 (30.7\%) being novel. iFGF23 levels and severity of the disease did not correlate significantly with truncating and non-truncating mutations or $\mathrm{N}$-terminal and $\mathrm{C}$-terminal PHEX mutations. This study provides a comprehensive description of the clinical profiles, circulating levels of iFGF23 and gene mutation features of patients with XLH, further enriching the genotypic spectrum of the diseases. The findings show no evident correlation of circulating iFGF23 levels with the age or disease severity in patients with XLH.

Keywords: X-linked hypophosphatemia, clinical features, mutational spectrum, intact fibroblast growth factor-23, genotype-phenotype correlation

\section{INTRODUCTION}

X-linked hypophosphatemia (XLH, OMIM 307800), a rare disorder of phosphorus metabolism, is the most common heritable form of rickets, with an incidence of approximately one in 20,000 births (Carpenter, 1997). The primary physiological trait of the disease is leakage of phosphate from the kidney, which leads to hypophosphatemia and defects in bone mineralization. 
$\mathrm{XLH}$ is caused by inactivating dominant mutations in the phosphate-regulating endopeptidase homolog X-linked (PHEX) gene. The PHEX gene is located on Xp22.1 and exhibits homology with a family of zinc metalloproteases, including neprilysin (NEP), the Kell antigen (KELL) and endothelin-converting enzymes 1 and 2 (ECE-1 and ECE-2) (Francis et al., 1997). PHEX is expressed in osteocytes and odontoblasts, and loss-of-function PHEX mutation results in excess circulating fibroblast growth factor 23 (FGF23), leading to hypophosphatemia (Kinoshita and Fukumoto, 2018). However, studies to date on circulating levels of FGF23 in XLH patients are contradictory. For example, several studies report elevated serum intact FGF23 (iFGF23) values in the majority of patients with XLH (Yamazaki et al., 2002; Jonsson et al., 2003; Zhang et al., 2019), whereas another study indicates serum iFGF23 values virtually in the reference range (Weber et al., 2003). Thus, we conducted a study to determine circulating iFGF23 concentrations in XLH patients.

For decades, conventional therapy (multiple daily doses of oral phosphate and calcitriol) was the only treatment option for patients with XLH; the partial efficacy of this approach has been indicated in several reports (Verge et al., 1991; Mäkitie et al., 2003a; Fuente et al., 2017). However, long-term treatment is frequently accompanied by a series of complications (Santos et al., 2013; Linglart et al., 2014). Recently, a new targeted therapy for XLH, i.e., the recombinant human monoclonal antibody against FGF-23 burosumab, has been approved in the United States and Europe and has achieved significantly greater therapeutic effect and safety in patients with XLH than conventional therapy (Imel et al., 2019). Because this new therapy will soon be available in China, a depiction of the general traits of Chinese individuals with XLH is important. Our center has previously reported several XLH cases in the Chinese population (Kang et al., 2012; Yue et al., 2014; Li et al., 2016); however, these reports do not comprehensively summarize the clinical and genetic characteristics of XLH patients because of their small sample sizes. Hence, we conducted this study by enlarging the study population to further systematically delineate the clinical and genetic spectrum of XLH and to explore circulating iFGF23 levels in these patients and their relationship with clinical and genetic parameters.

\section{MATERIALS AND METHODS}

\section{Subjects}

This study was approved by the Ethics Committee of Shanghai Jiao Tong University Affiliated Sixth People's Hospital. This study retrospectively reviewed the clinical and molecular features of 153 patients with XLH who were identified with PHEX gene mutations from 2008 to 2019. These patients included 87 familial cases and 66 sporadic cases, from 105 unrelated pedigrees. Hypophosphatemic patients with other causes (autosomal dominant hypophosphatemic rickets, autosomal recessive hypophosphatemic rickets, tumorinduced osteomalacia, hereditary hypophosphatamic rickets with hypercalciuria, etc.) were excluded in this study. One hundred and sixteen of the 153 patients were orally administered phosphate $20-40 \mathrm{mg} / \mathrm{kg}$ per day divided into five doses per day and calcitriol $0.25-0.5 \mu \mathrm{g}$ per day; follow-up data for these patients were recorded when available.

\section{Clinical Features}

Basic information was collected, including sex, age at diagnosis, and height converted into standard deviation scores (SDS) using standardized growth charts for Chinese children and adolescents (Li et al., 2009). Clinical rachitic signs or symptoms in these patients were recorded (bowed lower extremities, abnormal gait, short stature, dental disease, etc.). Radiography of bilateral posteroanterior wrists and knees was performed, and the Rickets Severity Score (RSS) was evaluated using Thacher's method (Thacher et al., 2000). The severity score of rickets is scaled from 0 (normal) to 10 (severe).

\section{Biochemical Measurements}

Relevant biochemical tests included serum phosphorus, calcium, total alkaline phosphatase (ALP), intact parathyroid hormone (PTH), 25-hydroxy-vitamin D (25OHD), $\beta$-CrossLaps of type 1 collagen containing cross-linked C-telopeptide ( $\beta$-CTX), and serum osteocalcin (OC), in the form of $\mathrm{N}$-terminal mid-molecule fragments and creatinine.

Serum phosphorus, calcium, and ALP levels were measured using a Hitachi 7,600-020 automatic biochemistry analyzer. Serum PTH, 25OHD, $\beta$-CTX, and OC concentrations were assessed using an automated Roche electrochemiluminescence system.

\section{Serum iFGF23 Measurement}

Serum samples were collected to measure iFGF23 levels at each patient's first visit to Shanghai Jiao Tong University Affiliated Sixth People's Hospital. All samples were stored at $-80^{\circ} \mathrm{C}$ until analysis. In total, 62 samples were available for measuring iFGF23. Serum iFGF23 levels were evaluated using a two-site ELISA kit (KAINOS Laboratories, Inc., Tokyo, Japan) with a detectable concentration range from 3 to $800 \mathrm{pg} / \mathrm{ml}$. The reference range for serum iFGF23 is $16.1-42.2 \mathrm{pg} / \mathrm{mL}$ (Zhang et al., 2019).

\section{Sanger Sequencing for PHEX Gene Mutations}

Genomic DNA was extracted from peripheral blood leukocytes using a DNA extraction kit (Lifefeng Biotech, Shanghai). The DNA sequence for the PHEX gene was obtained from an online database (GenBank accession NO. NC _000012.). The PCR and sequencing primers were the same as those used in our previous study and were designed using Primer 3 software ${ }^{1}$. All 22 exons and exon-intron boundaries of the PHEX gene were amplified by polymerase chain reaction (PCR). Direct sequencing was performed using BigDye Terminator Cycle Sequencing Ready Reaction Kit, version 3.1 (Applied Biosystems, Foster, CA, United States), and the product was analyzed with an automated ABI 3730 sequencer (Foster, CA, United States).

\footnotetext{
${ }^{1}$ http://bioinfo.ut.ee/primer3-0.4.0/
} 
Single-nucleotide polymorphisms (SNPs) were identified using Polyphred $^{2}$ and novel mutations using HGMD.

\section{Multiplex Ligation-Dependent Probe Amplification Analysis}

Multiplex ligation-dependent probe amplification (MLPA) analysis was performed to detect large deletion/duplication mutations in patients for whom direct DNA sequencing did not reveal PHEX mutations. MLPA analysis was performed according to the manufacturer's instructions (Salsa MLPA Kit P223 PHEX, Version 01, MRC-Holland, Amsterdam, Netherlands), and the product was analyzed using an ABI 3730XL sequencer (Applied Biosystems, Foster City, CA, United States) and the Coffalyser software program (MRC-Holland, Amsterdam, Netherlands).

\section{Statistical Analyses}

All data were analyzed using IBM SPSS Statistics (version 26.0; SPSS Inc., Chicago, IL, United States). The KolmogorovSmirnov test was employed to detect the normality of the distribution of continuous variables. Normally distributed data are presented as the mean $\pm \mathrm{SD}$, and between-group differences were assessed with independent-sample $t$ tests. Non-normally distributed data are expressed as medians (25th and 75th percentiles), and intergroup differences were evaluated with the Mann-Whitney $U$ test. Categorical variables are described as frequencies or percentages, and intergroup comparisons were analyzed with Fisher's exact test. Correlations between continuous variables were analyzed with the Spearman rank correlation coefficient. A two-tailed value of $P<0.05$ was considered statistically significant.

\section{RESULTS}

\section{Demographics and Clinical Features of XLH Patients}

The study cohort included 153 patients belonging to 105 unrelated pedigrees: 87 were familial cases and 66 were sporadic cases. Of the 153 patients, 45 were male, and 108 female, with a median age and a median onset age of 23.0 years (range: $1.3-$ 73.0 years) and 18.0 months (range: 9.0 months-26.0 years), respectively. The average height SDS for juveniles and adults was $-2.3 \pm 1.4$ and $-4.6 \pm 2.1$, respectively. According to further statistical analysis, adult patients showed significantly lower height SDS than juvenile patients $(P<0.001)$, which revealed a lasting effect on stature development during a long period of non-treatment. The most frequent manifestation of XLH in our center was bowed lower extremities, which accounted for $79.1 \%$ (121/153), followed by abnormal gait (106/153), short stature, growth retardation (106/153), dental disease (47/153), bone pain (28/153), and fracture (24/153) (Table 1). Lower-limb deformity or abnormal gait became apparent at a median age of 18.0 months. Based on radiographic manifestations, many patients had metaphyseal abnormalities of the distal femur,

${ }^{2}$ http://droog.mbt.washington.edu/poly_get.html
TABLE 1 | Characteristics of 153 patients with XLH.

\begin{tabular}{lc}
\hline Clinical characteristics & All patients $(\boldsymbol{n}=\mathbf{1 5 3})$ \\
\hline Sex (Female: male), $n$ & $108: 45$ \\
Mean age, years & 23.0 \\
Mean onset age, months & 18.0 \\
Height (SDS ${ }^{\text {) }}$ & \\
$\quad$ Juveniles, mean \pm SD & $-2.3 \pm 1.4$ \\
Adults, mean \pm SD & $-4.6 \pm 2.1$ \\
Bowed lower extremities, $n$ & 121 \\
Abnormal gait, $n$ & 106 \\
Short stature, growth retardation, $n$ & 106 \\
Dental disease, $n$ & 47 \\
Bone pain, $n$ & 28 \\
Fracture, $n$ & 24 \\
Rachitic rosary, $n$ & 14 \\
RSS ${ }^{b}$, mean \pm SD & $4.8 \pm 2.2$ \\
\hline
\end{tabular}

asDS, standard deviation score.

${ }^{b} R S S$, rickets severity score.

proximal tibia, and distal radius and ulna, with a mean RSS score of $4.8 \pm 2.2$ for juveniles $(n=34)$.

\section{Biochemical Characteristics of XLH}

Table 2 provides the biochemical characteristics of patients with XLH. Mean serum phosphorus was lower than the reference range established for all age groups (Ruppe, 1993). In addition, serum ALP values were greatly above the upper limit of normal in the juvenile group but were normal in the adult group. Furthermore, 54.4\% of patients had serum PTH levels higher than the upper limit of normal, though serum calcium was within the normal range $(n=79)$, and $59.8 \%$ of patients had vitamin $\mathrm{D}$ deficiency $(n=82)$.

\section{Serum iFGF23 Measurement}

Serum iFGF23 values were determined for 62 patients and displayed a wide variation from 14.39 to $730.70 \mathrm{pg} / \mathrm{ml}$, with a median value of $91.88 \mathrm{pg} / \mathrm{ml}$. For pediatric patients $(n=31)$, the median value of circulating iFGF23 was $94.87 \mathrm{pg} / \mathrm{ml}$ (interquartile range: $74.27-151.86 \mathrm{pg} / \mathrm{ml})$, and $96.8 \%(30 / 31)$ of patients had a high level of serum iFGF23 $(>42.2 \mathrm{pg} / \mathrm{ml})$. For adult patients $(n=31)$, the median value of circulating iFGF23 was $72.82 \mathrm{pg} / \mathrm{ml}$ (interquartile range: $39.42-136.00 \mathrm{pg} / \mathrm{ml}$ ), with $74.2 \%(23 / 31)$ having levels in the high range (Table 3$)$. Despite the lack of difference in serum iFGF23 levels between these two groups $(P=0.062)$, the proportion of pediatric patients with high levels of circulating iFGF23 $(>42.2 \mathrm{pg} / \mathrm{ml})$ was higher than that of adult patients $(P=0.026)$.

Correlation analysis demonstrated that serum iFGF23 levels had no relationship with the serum phosphate/upper limit ratio, age, onset age, height SDS or RSS (Table 4).

\section{Treatment and Following-up}

Forty-seven $(40.5 \%)$ of the $116 \mathrm{XLH}$ patients who were treated with phosphate and calcitriol daily received follow-up; 28 were children, and 19 were adults, with a median follow-up duration of 
TABLE 2 | Biochemical features of patients with XLH.

\begin{tabular}{|c|c|c|}
\hline Biochemical parameters & Age groups & \\
\hline \multirow[t]{4}{*}{ Serum phosphorus, mmol/L } & $1-3$ years & $0.84 \pm 0.20^{a}$ \\
\hline & 4-11 years & $0.79(0.71-0.87)^{b}$ \\
\hline & $12-15$ years & $0.75 \pm 0.11$ \\
\hline & $>15$ years & $0.61 \pm 0.11$ \\
\hline Serum calcium, mmol/L & & $2.34 \pm 0.12$ \\
\hline \multirow[t]{3}{*}{ ALP, U/L } & $1-15$ years & $585.5 \pm 195.9$ \\
\hline & 16-18 years & $388.7 \pm 210.7$ \\
\hline & $>18$ years & $94.0(82.5-146.0)$ \\
\hline PTH, pg/ml & & 69.80 (56.39-86.28) \\
\hline $25 O H D, n g / m l$ & & $17.84(12.50-29.63)$ \\
\hline iFGF23, pg/ml & & 91.88 (55.88-143.31) \\
\hline$\beta-C T X, n g / L$ & & $1,387.00(491.00-2444.00)$ \\
\hline $\mathrm{OC}, \mathrm{ng} / \mathrm{ml}$ & & 51.85 (21.38-99.55) \\
\hline Serum creatinine, $\mu \mathrm{mol} / \mathrm{L}$ & & $33.62 \pm 13.62$ \\
\hline
\end{tabular}

aNormally distributed data are shown as the mean $\pm S D$.

${ }^{b}$ Non-normally distributed data are shown as the median (interquartile range). ALP, total alkaline phosphatase; PTH, parathyroid hormone; 25OHD, 25-hydroxyvitamin $D ; \beta$-CTX, $\beta$-CrossLaps of type 1 collagen containing cross-linked C-telopeptide; OC, serum osteocalcin in the form of an N-terminal midmolecule fragment.

Normal range: phosphorus [varies by age (Ruppe, 1993)]: 1-3 years: 1.25$2.10 \mathrm{mmol} / \mathrm{L}, 4-11$ years: $1.20-1.80 \mathrm{mmol} / \mathrm{L}, 12-15$ years: $0.95-1.75 \mathrm{mmol} / \mathrm{L}$,

> 15 years: $0.80-1.60 \mathrm{mmol} / \mathrm{L}$, calcium: $2.08-2.60 \mathrm{mmol} / \mathrm{L}$, ALP: $1-15$ years: $42-$ 390 U/L (Zhang et al., 2019), 16-18 years: 52-171 U/L (Zhang et al., 2019), > 18 years: $15-112 \mathrm{U} / \mathrm{L}$, PTH: $15-65 \mathrm{pg} / \mathrm{mL}, 250 H \mathrm{D}:>30 \mathrm{ng} / \mathrm{ml}$, iFGF23: $16.1-$ $42.2 \mathrm{pg} / \mathrm{mL}$ (Zhang et al., 2019), $\beta$-CTX: 278-540 ng/L (Hu et al., 2013), OC: 13.07-27.68 ng/mL (Hu et al., 2013), creatinine: 53.0-115.0 $\mu \mathrm{mol} / \mathrm{L}$.

TABLE 3 | Distribution of serum iFGF23 levels in pediatric and adult patients with $\mathrm{XLH}(n=62)$.

\begin{tabular}{lcc}
\hline & Serum iFGF23 levels, $\mathbf{p g} / \mathbf{m l}$ & No. (\%) \\
\hline Pediatric patients, $n=31$ & $94.87(74.27-151.86)$ & 0 \\
Low & Medium & $1(3.2 \%)$ \\
Adult patients, $n=32$ & High & $30(96.8 \%)$ \\
& (39.42-136.00) & \\
& Low & $1(3.2 \%)$ \\
& Medium & $7(22.6 \%)$ \\
& High & $23(74.2 \%)$ \\
\hline
\end{tabular}

Low: Serum iFGF23 levels $<16.1 \mathrm{pg} / \mathrm{ml}$.

Medium: Serum iFGF23 levels $\geq 16.1$ and $\leq 42.2 \mathrm{pg} / \mathrm{ml}$.

High: Serum iFGF23 levels > $42.2 \mathrm{pg} / \mathrm{ml}$.

TABLE 4 | Correlation analyses of circulating iFGF23 and other clinical and biochemical parameters.

\begin{tabular}{lcr}
\hline Clinical and biochemical parameters & \multicolumn{2}{c}{ Serum iFGF23 } \\
\cline { 2 - 3 } & $r$ & $P$ value \\
\hline Age & -0.195 & 0.133 \\
Age of onset & -0.077 & 0.590 \\
Serum phosphate/Upper limit ratio & -0.195 & 0.159 \\
Height SDS & 0.259 & 0.064 \\
RSS & -0.235 & 0.305
\end{tabular}

12.0 months (3.0-120.0 months). For both groups, no significant increase in serum phosphorus level $(P=0.511 ; P=0.651)$ or decrease in serum ALP $(P=0.434 ; P=0.442)$ was observed at the median follow-up.

\section{Mutation Analysis of the PHEX Gene}

A total of 88 different mutations were identified in 153 patients, including 15 missense mutations (17.0\%), 15 nonsense mutations (17.0\%), 21 splicing mutations (23.9\%), 18 small deletions (20.5\%), four small insertions (4.5\%), and 15 gross deletions/duplications (17.0\%). Of the 88 mutations, 27 (30.7\%) were novel mutations not found in HGMD or reported in the literature. All the PHEX mutations identified in the present study are listed in Supplementary Table 1.

Seventy-three point mutations, including missense mutations, non-sense mutations, splice-site mutations, and small insertions/deletions, are scattered throughout the PHEX coding sequence and flanking intronic sequences, with $80.8 \%$ of point mutations in the $5^{\prime}$ region (up to amino acid 649 in exon 19) and the other $19.2 \%$ in the $3^{\prime}$ region (amino acid 650 to the $3^{\prime}$ end of PHEX); no mutations were detected in the $3^{\prime}$-untranslated regions (UTR) or $5^{\prime}$-UTR (Figure 1). The most frequent point mutations were R702X and R549X, which accounted for $4.1 \%(3 / 73)$ and $4.1 \%(3 / 73)$ of all point mutations, respectively.

\section{Genotype-Phenotype Association Analysis}

We divided the genotypes of the 153 patients into two groups, truncating mutations (non-sense mutations, deletions, insertions, and splice-site mutations, $n=124)$ and nontruncating mutations (missense mutations, $n=29$ ), and explored the phenotypic severity of the groups. The results showed no significant difference in terms of the serum phosphate/upper limit ratio, serum ALP/upper limit ratio and iFGF23, age of onset, or RSS and height SDS. Because residues 1-649 of the PHEX protein include several functional domains, such as the transmembrane domain and the two zinc-binding motifs, mutations in these locations might result in a more severe phenotype (Holm et al., 2001). Therefore, we divided another two groups: N-terminal mutations (from $5^{\prime}$ end to amino acid residue 649, $n=105$ ) and C-terminal mutations (from residue 650 to the $3^{\prime}$ end of PHEX, $n=24$ ) to verify the above hypothesis. However, no significant difference in the serum phosphate/upper limit ratio, serum ALP/upper limit ratio, iFGF23, age of onset, RSS, or height SDS was observed between the two groups (Table 5).

\section{DISCUSSION}

The present study describes the phenotypic characteristics and genotypic spectra of 153 pediatric and adult patients with XLH. Apparently, patients with XLH in China have similar symptoms to those of XLH patients in Western countries. Indeed, most patients present symptoms of rachitic skeletal deformities during childhood (Kinoshita and Fukumoto, 2018). 


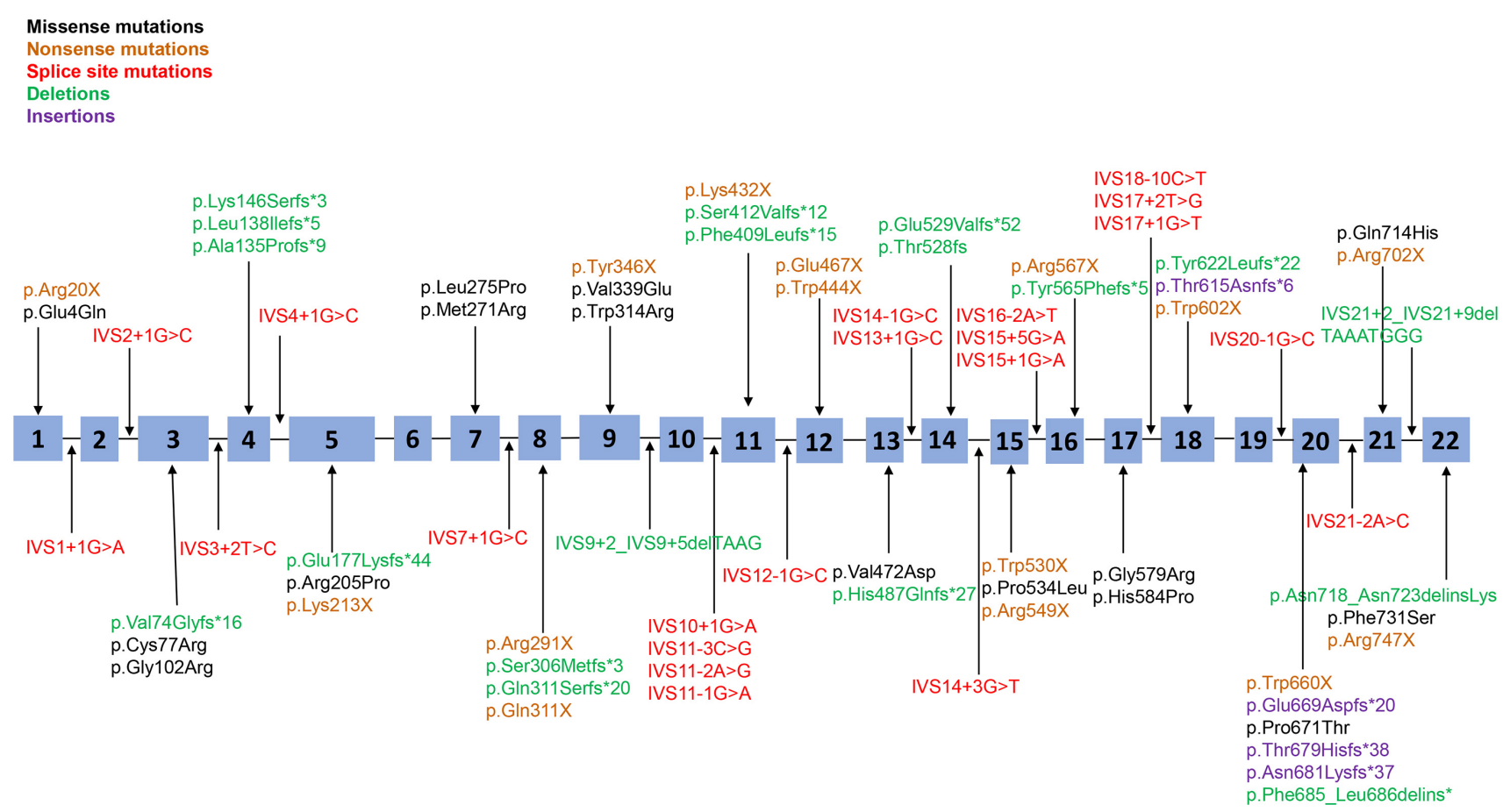

FIGURE 1 | Distribution of all point mutations identified in this study. A total of 73 point mutations (including missense mutations, non-sense mutations, splice-site mutations, and small insertions/deletions) were scattered throughout the 22 exons and adjacent intron areas of the PHEX gene. Black corresponds to missense mutations, yellow corresponds to non-sense mutations, red corresponds to splice-site mutations, green corresponds to small deletions, and purple corresponds to small insertions.

TABLE 5 | Genotype-phenotype correlation in patients with XLH.

\begin{tabular}{|c|c|c|c|c|c|c|}
\hline & $\begin{array}{l}\text { Truncating mutations } \\
\qquad(n=124)\end{array}$ & $\begin{array}{c}\text { Non-truncating } \\
\text { mutations }(n=29)\end{array}$ & $P$ value & $\begin{array}{l}\text { N-terminal mutations } \\
\qquad(n=105)\end{array}$ & $\begin{array}{l}\text { C-terminal mutations } \\
\qquad(n=24)\end{array}$ & $P$ value \\
\hline Onset age (years) & $1.5(1.0-2.0)$ & $1.2(1.0-3.0)$ & 0.996 & $1.5(1.0-2.0)$ & $1.8(1.2-3.0)$ & 0.360 \\
\hline Height SDS & $-3.5 \pm 2.2$ & $-3.9 \pm 2.0$ & 0.510 & $-3.5 \pm 2.2$ & $-3.4 \pm 1.9$ & 0.759 \\
\hline Serum phosphate/Upper limit ratio & $0.40 \pm 0.09$ & $0.41 \pm 0.07$ & 0.925 & $0.40 \pm 0.08$ & $0.43 \pm 0.12$ & 0.286 \\
\hline Serum ALP/Upper limit ratio & $1.29 \pm 0.56$ & $1.23 \pm 0.42$ & 0.700 & $1.36 \pm 0.57$ & $1.05 \pm 0.36$ & 0.077 \\
\hline Serum iFGF23 (pg/mL) & 91.38 (60.96-141.99) & $\begin{array}{c}112.55 \\
(40.74-337.53)\end{array}$ & 0.695 & $90.93(53.55-142.08)$ & $107.23(72.07-160.31)$ & 0.485 \\
\hline RSS & $4.8 \pm 2.2$ & $5.0 \pm 4.2$ & 0.895 & $5.0 \pm 2.2$ & $4.4 \pm 2.6$ & 0.538 \\
\hline
\end{tabular}

In pediatric patients, their parents frequently discover lowerlimb abnormities, or waddling gaits when they just learn to walk. A consensus statement of clinical practice for XLH (Haffner et al., 2019) indicates that rachitic skeletal characteristics usually occur at 6 months after birth and that waddling gait and lower-limb deformities become apparent at the age of 2 years. Correspondingly, our study showed that patients manifested bowed lower extremities or abnormal gait at a median age of 18.0 months.

Patients with XLH at our center exhibited typical biochemical traits, similar to those in Western countries. Ninety-five percent of these patients displayed decreased levels of serum phosphorus below the age-related reference range because of renal phosphate wasting, which is a result of increasing serum FGF23. Our study reported that $85.5 \%(53 / 62)$ of patients had serum iFGF23 levels above the upper limit of the reference range. However, there were still $12.9 \%(8 / 62)$ of patients having serum iFGF23 levels within the reference range, which suggested that serum iFGF23 in patients with XLH is very likely associated with other metabolic factors, such as serum PTH, circulating $\alpha$-Klotho, hypoxia, and inflammatory cytokines, in addition to serum phosphate (Courbebaisse and Lanske, 2018). On the other hand, the serum concentration of iFGF23 is regulated by serum phosphate (Hori et al., 2016), serum FGF-23 is positively correlated with serum phosphate; hence, this "normal" FGF-23 in these patients can be considered inappropriately normal. It is worth mentioning that a 24-year-old woman who sought a medical consultation in 2014 had circulating iFGF23 levels under the reference range. We speculated the inappropriate level of iFGF23 in this patient might be due to the presence of hypophosphatemia; moreover, 
partial degradation of serum iFGF23 during long-term storage at $-80^{\circ} \mathrm{C}$ may have resulted in the low level of iFGF23 for this patient. An in vitro study by Liu et al. (2003) illustrated that FGF23 is not the direct substrate cleaved by PHEX; in fact, the mechanism by which PHEX mutation causes overproduction of FGF23 remains unknown, and further study is required to clarify the pathogenesis.

To evaluate renal phosphate wasting, the tubular maximum reabsorption of phosphate per glomerular filtration rate (TmP/GFR) should be calculated clinically (Haffner et al., 2019). Unfortunately, we did not perform this, and further detection is needed to better evaluate the disease. Secondary hyperparathyroidism (SHPT), a typical property of XLH, was observed in $54.4 \%$ of patients prior to treatment in our center. Studies by DeLacey et al. (2019) and Rafaelsen et al. (2016) have also described the high prevalence of SHPT, at $83.3 \%(70 / 84)$ and $66.7 \%(10 / 15)$, respectively, in patients with XLH. Several factors may be associated with SPHT in patients with XLH. For those who receive treatment, prolonged oral phosphate induces intermittently elevated serum phosphate concentrations, with recurrent stimulation of the parathyroid glands (Mäkitie et al., 2003b); accordingly, calcitriol is required in combination with oral phosphate supplements in clinical practice to minimize the risks of SHPT. For those who have never received phosphate therapy, a reduced circulating level of $1,25(\mathrm{OH})_{2} \mathrm{D}$ due to excess FGF-23 is very likely the main factor involved in the development of hyperparathyroidism. In addition, loss of PHEX function in the parathyroid gland leading to abnormal PTH mRNA cleavage or degradation may be responsible for the occurrence of SPHT (Lecoq et al., 2020).

Until now, conventional therapy (phosphate salts and calcitriol) has been regarded as the first-line treatment option for patients with XLH in China. To assess the efficacy and safety of conventional therapy, serum ALP levels are suggested to be a reliable biomarker of rickets (Chesney et al., 1983; Tsuru et al., 1987; Linglart et al., 2014). In the present study, no improvement in serum ALP level was noted during the 1-year treatment follow-up. This may be explained by the notion that treating XLH with conventional therapy will increase circulating FGF23, which to some extent diminishes the therapeutic effect (Imel et al., 2010).

We identified PHEX gene mutations in this population-based cohort and found 88 different mutations in 153 patients. Of the 88 PHEX variants, $30.7 \%$ have never been reported, indicating that PHEX gene mutations are private (Rafaelsen et al., 2016).

Fifteen different missense mutations were identified in this study, of which six (40\%) are novel. All missense mutations we detected occur at residues that are highly conserved in mammals. The mutation $\mathrm{C} 77 \mathrm{R}$ is located at the site where five of the 10 conserved cysteine residues are clustered at the C-terminus of the transmembrane domain (Sabbagh et al., 2000). Consequently, such a mutation most likely disrupts disulfide bond formation and alters the secondary structure of the protein by influencing folding, leading to instability and dysfunction of the protein (Rowe et al., 1997). Additionally, G579R is very likely a mutational hot spot because approximately 20 unrelated patients of distinct races are reported to harbor this mutation
(Popowska et al., 2000; Sabbagh et al., 2000, 2001, 2003; Durmaz et al., 2013; Radlović et al., 2014; Lin et al., 2018; Zhang et al., 2019). Our center detected the same mutation in a 3year-old boy. G579 is adjacent to the highly conserved zincbinding motif (HEFTH), a major fingerprint of the M13 family of metallopeptidases. Evidence-based research has demonstrated that the G579R mutation attenuates the function of the PHEX protein by altering protein trafficking, endopeptidase activity, and protein conformation (Sabbagh et al., 2003).

Non-sense and splicing site mutations are considered to cause truncation of the PHEX protein, resulting in loss of function. In the present study, the first N-terminal non-sense mutation was encountered in exon 1 (R20X), with this nonsense mutation segregating in two families. The R20X mutation is predicted to result in degradation of the mRNA through nonsense-mediated mRNA decay, thereby abrogating synthesis of a truncated protein (Sabbagh et al., 2000; Charoenngam et al., 2019). Another stop mutation in exon 21 (R702X), despite being located in the $3^{\prime}$ end of PHEX, has been proven to be deleterious. This mutant lacks two conserved cysteine residues, causing protein structure alteration and indicating that the end of N-terminal amino acids still has an important role in PHEX function. Among the 21 splicing site mutations in the current study, 12 are splice donor mutations, and nine are splice acceptor mutations. These splicing mutations result in major changes in the secondary structure of the PHEX protein via exon skipping, intron retention, and activation of cryptic splice sites (BinEssa et al., 2019).

The genotype-phenotype correlation of the PHEX gene mutation in XLH has not been well established, and scholars have followed genotype-phenotype correlation research with great interest, particularly regarding the relationship between phenotype and mutation type or location (Holm et al., 2001; Cho et al., 2005; Rafaelsen et al., 2016; Zhang et al., 2019; Zheng et al., 2020). An evidence-based study by Zheng et al. (2020) has revealed that the severity of the disease is not related to truncating or non-truncating mutations, as based on their experimental finding that truncating and non-truncating variants possess a similar functional portrait. Nevertheless, a study by Zhang et al. (2019) has concluded that patients with mutations in the $5^{\prime}$ region of $P H E X$ have an earlier age of onset and higher circulating levels of iFGF23 than those with mutations in the $3^{\prime}$ region of the gene. Moreover, a study by Holm et al. (2001) has revealed no relationship between disease severity and the type or location of the mutation, despite a trend toward a more severe skeletal phenotype in familial patients with truncating mutations $(P=0.072)$. In conformity with the reports by Zheng et al. and Holm et al. no correlation between phenotype severity and truncating and non-truncating mutations or N-terminal and C-terminal mutations was found in our study.

In conclusion, our retrospective study broadens the genotypic spectrum of XLH. We have identified 88 different mutations in 153 Chinese patients with XLH, and 27 of the mutations have never been reported. Furthermore, the present study has determined circulating iFGF23 levels in XLH patients and found no relationship with age, onset age, severity of the disease or mutation type. 


\section{DATA AVAILABILITY STATEMENT}

The datasets presented in this study can be found in online repositories. The names of the repository/repositories and accession number(s) can be found in the article/Supplementary Material.

\section{ETHICS STATEMENT}

The studies involving human participants were reviewed and approved by Ethics Committee of Shanghai Jiao Tong University Affiliated Sixth People's Hospital. Written informed consent to participate in this study was provided by the participants' legal guardian/next of kin.

\section{AUTHOR CONTRIBUTIONS}

XL and SL conducted the study and analyzed the data. XL wrote the draft of the manuscript. ZZ and HY supervised the study and revised the manuscript. All authors read and approved the final manuscript.

\section{REFERENCES}

BinEssa, H. A., Zou, M., Al-Enezi, A. F., Alomrani, B., Al-Faham, M. S. A., Al-Rijjal, R. A., et al. (2019). Functional analysis of 22 splice-site mutations in the PHEX, the causative gene in X-linked dominant hypophosphatemic rickets. Bone 125, 186-193. doi: 10.1016/j.bone.2019.05.017

Carpenter, T. O. (1997). New perspectives on the biology and treatment of X-linked hypophosphatemic rickets. Pediatr. Clin. North Am. 44, 443-466. doi: 10.1016/ s0031-3955(05)70485-5

Charoenngam, N., Shirvani, A., and Holick, M. F. (2019). Vitamin D for skeletal and non-skeletal health: what we should know. J. Clin. Orthop. Trauma 10, 1082-1093. doi: 10.1016/j.jcot.2019.07.004

Chesney, R. W., Mazess, R. B., Rose, P., Hamstra, A. J., DeLuca, H. F., and Breed, A. L. (1983). Long-term influence of calcitriol (1,25-dihydroxyvitamin D) and supplemental phosphate in X-linked hypophosphatemic rickets. Pediatrics 71, 559-567.

Cho, H. Y., Lee, B. H., Kang, J. H., Ha, I. S., Cheong, H. I., and Choi, Y. (2005). A clinical and molecular genetic study of hypophosphatemic rickets in children. Pediatr. Res. 58, 329-333. doi: 10.1203/01.Pdr.0000169983.40758.7b

Courbebaisse, M., and Lanske, B. (2018). Biology of fibroblast growth factor 23: from physiology to pathology. Cold Spring Harb. Perspect. Med. 8:a031260. doi: 10.1101/cshperspect.a031260

DeLacey, S., Liu, Z., Broyles, A., El-Azab, S. A., Guandique, C. F., James, B. C., et al. (2019). Hyperparathyroidism and parathyroidectomy in X-linked hypophosphatemia patients. Bone 127, 386-392. doi: 10.1016/j.bone.2019. 06.025

Durmaz, E., Zou, M., Al-Rijjal, R. A., Baitei, E. Y., Hammami, S., Bircan, I., et al. (2013). Novel and de novo PHEX mutations in patients with hypophosphatemic rickets. Bone 52, 286-291. doi: 10.1016/j.bone.2012.10.012

Francis, F., Strom, T. M., Hennig, S., Böddrich, A., Lorenz, B., Brandau, O., et al. (1997). Genomic organization of the human PEX gene mutated in X-linked dominant hypophosphatemic rickets. Genome Res. 7, 573-585. doi: 10.1101/gr. 7.6.573

Fuente, R., Gil-Peña, H., Claramunt-Taberner, D., Hernández, O., FernándezIglesias, A., Alonso-Durán, L., et al. (2017). X-linked hypophosphatemia and growth. Rev. Endocr. Metab. Disord. 18, 107-115. doi: 10.1007/s11154-0179408-1

Haffner, D., Emma, F., Eastwood, D. M., Duplan, M. B., Bacchetta, J., Schnabel, D., et al. (2019). Clinical practice recommendations for the diagnosis and

\section{FUNDING}

This work was supported by the National Key Research and Development Program of China (No. 2018YFA0800801); National Natural Science Foundation of China (NSFC) (Nos. 81974126 and 81770874); the Clinical Science and Technology Innovation Project of Shanghai Shenkang Hospital Development Center (No. SHDC12018120); Shanghai Key Clinical Center for Metabolic Disease, Shanghai Health Commission Grant (No. 2017ZZ01013); and Shanghai Municipal Key Clinical Specialty.

\section{ACKNOWLEDGMENTS}

We thank all the participants recruited for this study.

\section{SUPPLEMENTARY MATERIAL}

The Supplementary Material for this article can be found online at: https://www.frontiersin.org/articles/10.3389/fcell.2021. 617738/full\#supplementary-material

management of X-linked hypophosphataemia. Nat. Rev. Nephrol. 15, 435-455 doi: 10.1038/s41581-019-0152-5

Holm, I. A., Nelson, A. E., Robinson, B. G., Mason, R. S., Marsh, D. J., Cowell, C. T. et al. (2001). Mutational analysis and genotype-phenotype correlation of the PHEX gene in X-linked hypophosphatemic rickets. J. Clin. Endocrinol. Metab. 86, 3889-3899. doi: 10.1210/jcem.86.8.7761

Hori, M., Kinoshita, Y., Taguchi, M., and Fukumoto, S. (2016). Phosphate enhances Fgf23 expression through reactive oxygen species in UMR-106 cells. J. Bone Miner. Metab. 34, 132-139. doi: 10.1007/s00774-015-0651-9

Hu, W. W., Zhang, Z., He, J. W., Fu, W. Z., Wang, C., Zhang, H., et al. (2013). Establishing reference intervals for bone turnover markers in the healthy shanghai population and the relationship with bone mineral density in postmenopausal women. Int. J. Endocrinol. 2013:513925. doi: 10.1155/2013/ 513925

Imel, E. A., DiMeglio, L. A., Hui, S. L., Carpenter, T. O., and Econs, M. J. (2010). Treatment of X-linked hypophosphatemia with calcitriol and phosphate increases circulating fibroblast growth factor 23 concentrations. J. Clin. Endocrinol. Metab. 95, 1846-1850. doi: 10.1210/jc.2009-1671

Imel, E. A., Glorieux, F. H., Whyte, M. P., Munns, C. F., Ward, L. M., Nilsson, O., et al. (2019). Burosumab versus conventional therapy in children with X-linked hypophosphataemia: a randomised, active-controlled, open-label, phase 3 trial. Lancet 393, 2416-2427. doi: 10.1016/s0140-6736(19)30654-3

Jonsson, K. B., Zahradnik, R., Larsson, T., White, K. E., Sugimoto, T., Imanishi, Y., et al. (2003). Fibroblast growth factor 23 in oncogenic osteomalacia and X-linked hypophosphatemia. N. Engl. J. Med. 348, 1656-1663. doi: 10.1056/ NEJMoa020881

Kang, Q. L., Xu, J., Zhang, Z., He, J. W., Lu, L. S., Fu, W. Z., et al. (2012). Three novel PHEX gene mutations in four Chinese families with X-linked dominant hypophosphatemic rickets. Biochem. Biophys. Res. Commun. 423, 793-798. doi 10.1016/j.bbrc.2012.06.042

Kinoshita, Y., and Fukumoto, S. (2018). X-linked hypophosphatemia and FGF23related hypophosphatemic diseases: prospect for new treatment. Endocr. Rev. 39, 274-291. doi: 10.1210/er.2017-00220

Lecoq, A. L., Brandi, M. L., Linglart, A., and Kamenický, P. (2020). Management of X-linked hypophosphatemia in adults. Metabolism 103:154049. doi: 10.1016/j. metabol.2019.154049

Li, H., Ji, C. Y., Zong, X. N., and Zhang, Y. Q. (2009). Height and weight standardized growth charts for Chinese children and adolescents aged 0 to 18 years. Zhonghua Er Ke Za Zhi 47, 487-492. 
Li, S. S., Gu, J. M., Yu, W. J., He, J. W., Fu, W. Z., and Zhang, Z. L. (2016). Seven novel and six de novo PHEX gene mutations in patients with hypophosphatemic rickets. Int. J. Mol. Med. 38, 1703-1714. doi: 10.3892/ijmm. 2016.2796

Lin, X., Zhu, Y., Luo, J., and Huang, J. (2018). Genetic analysis of three families with X-linked dominant hypophosphatemic rickets. J. Pediatr. Endocrinol. Metab. 31, 789-797. doi: 10.1515/jpem-2017-0451

Linglart, A., Biosse-Duplan, M., Briot, K., Chaussain, C., Esterle, L., GuillaumeCzitrom, S., et al. (2014). Therapeutic management of hypophosphatemic rickets from infancy to adulthood. Endocr. Connect. 3, R13-R30. doi: 10.1530/ ec-13-0103

Liu, S., Guo, R., Simpson, L. G., Xiao, Z. S., Burnham, C. E., and Quarles, L. D. (2003). Regulation of fibroblastic growth factor 23 expression but not degradation by PHEX. J. Biol. Chem. 278, 37419-37426. doi: 10.1074/jbc. M304544200

Mäkitie, O., Doria, A., Kooh, S. W., Cole, W. G., Daneman, A., and Sochett, E. (2003a). Early treatment improves growth and biochemical and radiographic outcome in X-linked hypophosphatemic rickets. J. Clin. Endocrinol. Metab. 88, 3591-3597. doi: 10.1210/jc.2003-030036

Mäkitie, O., Kooh, S. W., and Sochett, E. (2003b). Prolonged high-dose phosphate treatment: a risk factor for tertiary hyperparathyroidism in X-linked hypophosphatemic rickets. Clin. Endocrinol. 58, 163-168. doi: 10.1046/j.13652265.2003.01685.x

Popowska, E., Pronicka, E., Sułek, A., Jurkiewicz, D., Rowe, P., Rowinska, E., et al. (2000). X-linked hypophosphatemia in Polish patients. 1. Mutations in the PHEX gene. J. Appl. Genet. 41, 293-302.

Radlović, V., Smoljanić, Z., Radlović, N., Leković, Z., Ristić, D., Ducić, S., et al. (2014). X-linked hypophosphatemic rickets: case report. Srp. Arh. Celok. Lek. 142, 75-78. doi: 10.2298/sarh1402075r

Rafaelsen, S., Johansson, S., Rćder, H., and Bjerknes, R. (2016). Hereditary hypophosphatemia in Norway: a retrospective population-based study of genotypes, phenotypes, and treatment complications. Eur. J. Endocrinol. 174, 125-136. doi: 10.1530/eje-15-0515

Rowe, P. S., Oudet, C. L., Francis, F., Sinding, C., Pannetier, S., Econs, M. J., et al. (1997). Distribution of mutations in the PEX gene in families with X-linked hypophosphataemic rickets (HYP). Hum. Mol. Genet. 6, 539-549. doi: 10.1093/ hmg/6.4.539

Ruppe, M. D. (1993). "X-linked hypophosphatemia," in GeneReviews $\left({ }^{\circledR}\right)$, eds M. P. Adam, H. H. Ardinger, R. A. Pagon, S. E. Wallace, L. J. H. Bean, K. Stephens, et al. (Seattle, WA: University of Washington). Copyright $\odot$ 19932020, University of Washington, Seattle. GeneReviews is a registered trademark of the University of Washington, Seattle. All rights reserved.

Sabbagh, Y., Boileau, G., Campos, M., Carmona, A. K., and Tenenhouse, H. S. (2003). Structure and function of disease-causing missense mutations in the PHEX gene. J. Clin. Endocrinol. Metab. 88, 2213-2222. doi: 10.1210/jc.2002021809

Sabbagh, Y., Boileau, G., DesGroseillers, L., and Tenenhouse, H. S. (2001). Diseasecausing missense mutations in the PHEX gene interfere with membrane targeting of the recombinant protein. Hum. Mol. Genet. 10, 1539-1546. doi: $10.1093 / \mathrm{hmg} / 10.15 .1539$

Sabbagh, Y., Jones, A. O., and Tenenhouse, H. S. (2000). PHEXdb, a locus-specific database for mutations causing X-linked hypophosphatemia. Hum. Mutat. 16, 1-6. doi: 10.1002/1098-1004(200007)16:1<1::Aid-humu1<3.0.Co;2-j

Santos, F., Fuente, R., Mejia, N., Mantecon, L., Gil-Peña, H., and Ordoñez, F. A. (2013). Hypophosphatemia and growth. Pediatr. Nephrol. 28, 595-603. doi: 10.1007/s00467-012-2364-9

Thacher, T. D., Fischer, P. R., Pettifor, J. M., Lawson, J. O., Manaster, B. J., and Reading, J. C. (2000). Radiographic scoring method for the assessment of the severity of nutritional rickets. J. Trop. Pediatr. 46, 132-139. doi: 10.1093/tropej/ 46.3.132

Tsuru, N., Chan, J. C., and Chinchilli, V. M. (1987). Renal hypophosphatemic rickets. Growth and mineral metabolism after treatment with calcitriol $(1,25$ dihydroxyvitamin D3) and phosphate supplementation. Am. J. Dis. Child. 141, 108-110. doi: 10.1001/archpedi.1987.04460010108039

Verge, C. F., Lam, A., Simpson, J. M., Cowell, C. T., Howard, N. J., and Silink, M. (1991). Effects of therapy in X-linked hypophosphatemic rickets. N. Engl. J. Med. 325, 1843-1848. doi: 10.1056/nejm199112263252604

Weber, T. J., Liu, S., Indridason, O. S., and Quarles, L. D. (2003). Serum FGF23 levels in normal and disordered phosphorus homeostasis. J. Bone Miner. Res. 18, 1227-1234. doi: 10.1359/jbmr.2003.18.7.1227

Yamazaki, Y., Okazaki, R., Shibata, M., Hasegawa, Y., Satoh, K., Tajima, T., et al. (2002). Increased circulatory level of biologically active full-length FGF-23 in patients with hypophosphatemic rickets/osteomalacia. J. Clin. Endocrinol. Metab. 87, 4957-4960. doi: 10.1210/jc.2002-021105

Yue, H., Yu, J. B., He, J. W., Zhang, Z., Fu, W. Z., Zhang, H., et al. (2014). Identification of two novel mutations in the PHEX gene in Chinese patients with hypophosphatemic rickets/osteomalacia. PLoS One 9:e97830. doi: 10.1371/ journal.pone.0097830

Zhang, C., Zhao, Z., Sun, Y., Xu, L., JiaJue, R., Cui, L., et al. (2019). Clinical and genetic analysis in a large Chinese cohort of patients with X-linked hypophosphatemia. Bone 121, 212-220. doi: 10.1016/j.bone.2019.01.021

Zheng, B., Wang, C., Chen, Q., Che, R., Sha, Y., Zhao, F., et al. (2020). Functional characterization of PHEX gene variants in children with $\mathrm{X}$-linked hypophosphatemic rickets shows no evidence of genotype-phenotype correlation. J. Bone Miner. Res. 35, 1718-1725. doi: 10.1002/jbmr.4035

Conflict of Interest: The authors declare that the research was conducted in the absence of any commercial or financial relationships that could be construed as a potential conflict of interest.

Copyright (c) $2021 \mathrm{Lin}, \mathrm{Li}$, Zhang and Yue. This is an open-access article distributed under the terms of the Creative Commons Attribution License (CC BY). The use, distribution or reproduction in other forums is permitted, provided the original author(s) and the copyright owner(s) are credited and that the original publication in this journal is cited, in accordance with accepted academic practice. No use, distribution or reproduction is permitted which does not comply with these terms. 